\title{
A FiELD VEGETABLE TRANSPLANTER FOR USE IN BOTH TILLED AND NO-TILL SOILS
}

\author{
C. Frasconi, L. Martelloni, M. Raffaelli, M. Fontanelli, \\ L. Abou Chehade, A. Peruzzi, D. Antichi
}

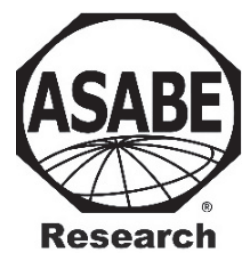

\begin{abstract}
A commercial, manually fed vegetable transplanter was modified and adapted to work in no-till soils. Details of the modifications are described in this article. The aim of this research was to evaluate the performance of this transplanter under actual field conditions in both tilled and no-till soils. The draft force in the no-till soil was measured for different working tools mounted for tilling or loosening a narrow band of soil before passing with the furrower. The combination of a ripper shank opener with a straight nose point resulted in the lowest draft force values per unit of working depth. The transplanter accuracy and transplant success rate were evaluated in different vegetable crops. The accuracy parameters (multiple index, miss index, quality of feed index, and precision) were estimated and in general were similar in the tilled and no-till soils, indicating that the transplanter was able to operate in both soil conditions with the same accuracy. The transplant success rates were also similar in both soil conditions. The transplanter thus offers a satisfactory technical solution for transplanting vegetables in both tilled and no-till soils.
\end{abstract}

Keywords. Conservation tillage, draft force, organic farming, transplanter accuracy, transplant success rate.

$\mathrm{T}$ Transplanting is one of the most labor intensive, low speed, and low work efficient operations in vegetable production, and the use of transplanters significantly reduces the costs compared to the manual operation (Prasanna Kumar and Raheman, 2008). Although transplanting into tilled soils is currently the most common practice among growers, the increasing interest in the adoption of conservation tillage strategies in field vegetable production requires the development and adaptation of new types of equipment (Morse, 1999). Conservation tillage is defined as "any tillage sequence, the object of which is to minimize or reduce loss of soil and water; operationally it is a tillage or a combination of tillage and planting which leaves a $30 \%$ or greater cover of crop residue on the surface" (SSSA, 1987). Transplanting seedlings in no-till soils by using custom-built or modified transplanters allows reduced management costs and provides the benefits of conservation agriculture. No tillage is considered the extreme form of conservation tillage, where the soil is left undisturbed before planting (Morse, 1999).

To achieve the best results, conservation tillage should be combined with the use of cover crops managed as living or dead mulch in order to cover the soil and prevent weed growth

Submitted for review in April 2018 as manuscript number MS 12896; approved for publication as a Research Article by the Machinery Systems Community of ASABE in January 2019.

The authors are Christian Frasconi, Postdoctoral Fellow, Luisa Martelloni, Postdoctoral Fellow, Michele Raffaelli, Full Professor, Marco Fontanelli, Postdoctoral Researcher, Lara Abou Chehade, Doctoral Student, Andrea Peruzzi, Full Professor, and Daniele Antichi, Postdoctoral Researcher, Department of Agriculture, Food, and Environment, University of Pisa, Italy. Corresponding author: Christian Frasconi, University of Pisa, Via del Borghetto 80, 56124 Pisa, Italy; phone: +39 0502218945; e-mail: christian.frasconi@unipi.it. and soil erosion risks. The main benefits of conservation tillage systems in general, and especially no-till systems coupled with cover crops, are increased soil fertility, improved field trafficability during inclement weather, and reduction in erosion problems, soil water evaporation, and tillage costs (Parish, 2005; Mazzoncini et al., 2011; Díaz-Pérez et al., 2012; Mitchell et al., 2012, 2017; Calegari et al., 2013).

The research community and vegetable growers began to pay attention to no-till production systems in the 1990s (Morse, 1999). The lack of reliable no-till transplanters and inconsistent seedling establishment have been the major factors limiting the adoption of no-till systems for transplanted field vegetables (Morse, 1999). To date, most no-till transplanters have been tested mainly by researchers as prototypes for experimental purposes and are not available on the market for commercial farmers (Morse, 1999; Yoder et al., 2005; Mitchell et al., 2012).

Data regarding the draft force, the transplant success rate, and accuracy indexes are the main parameters studied for evaluating transplanter performance in both tilled and no-till soils (Prasanna Kumar and Raheman, 2012; Nandede et al., 2014). The furrow opener and closer of a transplanter are designed to create a better physical environment around the seedlings, and these functions are directly related to the draft force (Nandede et al., 2014).

High-technology modifications made to transplanters for tilled soils have included automation of the feeding system (Tsuga, 2000; Parish, 2005; Prasanna Kumar and Raheman, 2012). The B\&B No-Till Company (Lauren Fork, Va.) has developed and commercialized a subsurface tiller-transplanter. This machine combines a subsurface soil loosener and a transplanter for tilled soils. The subsurface soil loosener tills a narrow strip of soil ahead of the transplanter's 
double-disc shoe. The double-disc shoe moves through the residue and tilled strips with relatively little penetration resistance and with minimal surface soil and residue disturbance. The machine is also equipped for precision fertilizer placement (Morse et al., 1993).

However, to the best of our knowledge, there are no previous studies in the literature reporting data on the performance of transplanters modified or built to work in no-till soils, nor of machines able to operate in both tilled and notill conditions. In this research, a commercial, manually fed vegetable transplanter ("Fast" model, Fedele Costruzioni Meccaniche, Lanciano, Italy) was modified and adapted to work in no-till soil. Details of the modifications made to the original version of the machine are described in this article. The aim of this research was to evaluate the performance of this transplanter under field conditions in both tilled and notill soils. The transplanter accuracy and the transplant success rate were evaluated in different vegetable crops. Transplanter accuracy was defined through indexes evaluating the times that the transplanter maintained the appropriate transplant distance and how precise this distance was, and the times that multiple or missing depositions of seedlings occurred. The transplant success rate was the ratio between the successful plantings and the total number of seedlings dropped. The draft force in no-till soil was measured to estimate the draft force values per unit of working depth for different combinations of working tools.

\section{Materials ANd Methods DESCRIPTION OF TRANSPLANTER AND MODIFICATIONS}

A commercial, manually fed, mounted vegetable transplanter (Fedele, 2017) was modified and adapted to work in no-till soil (fig. 1). The machine is modular, which means that it can be equipped with a varying number (1 to 6) of seedling transplant units. The seedling transplant units are mounted on the main frame where the transplanter linkage points, which couple with the tractor's three-point hitch, are also mounted. Each seedling transplant unit is composed of a fixed part, which is mounted directly to the main frame; the fixed part includes a spring that regulates the load of the

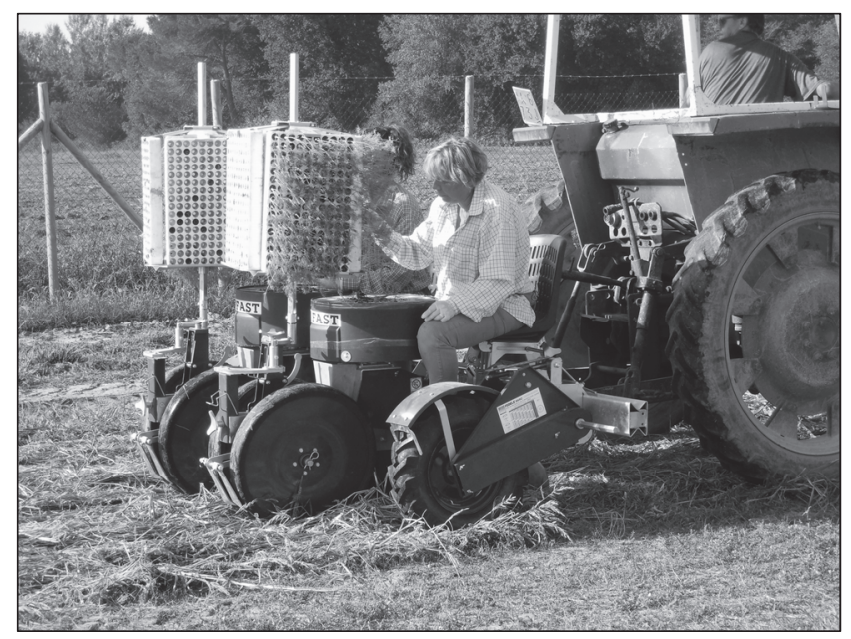

Figure 1. Two-row vegetable transplanter working in no-till soil. pivoting part, which includes the feeding system, furrower, and press wheels (fig. 2). Pivoting is required to maintain the right transplant depth and to reduce the risk of breakdown in stony soils. The transplanter is manually fed. One operator per row picks seedlings from tray pots and places them into a rotary horizontal carousel with 12 cups. When a seedling is placed into the carousel, the bottom of the cup is opened in correspondence of the furrower, and the seedling drops down into it. A kicker then pushes the seedling into the open furrow, and a pair of adjustable press wheels, tilted outward at the top, close the furrow.

Two pneumatic ground-driven wheels (fig. 2) provide the motion for the rotary carousel and the kicker, ensuring that each transplanting action is synchronized with the forward speed. Vertical adjustment of these wheels controls the transplant depth. By changing the gear ratio of the chain drive of the wheels, different transplanting distances (plant spacing) along the row are obtained. The minimum configuration for seedling placement is a distance of $50 \mathrm{~cm}$ between rows (row spacing) and $9 \mathrm{~cm}$ within the row (plant-to-plant spacing). The seedling cell shape can be conical or pyramidal and must not be larger than $3.5 \mathrm{~cm}$ in diameter.

To transplant in no-till soil, various modifications were made to the machine described above and shown in figures 1 and 2. A $30 \mathrm{~cm}$ diameter smooth coulter (manufactured by OFAS S.p.a., Mussolente, Vicenza, Italy) (fig. 3) was mounted on the fixed part of the transplanter, directly under

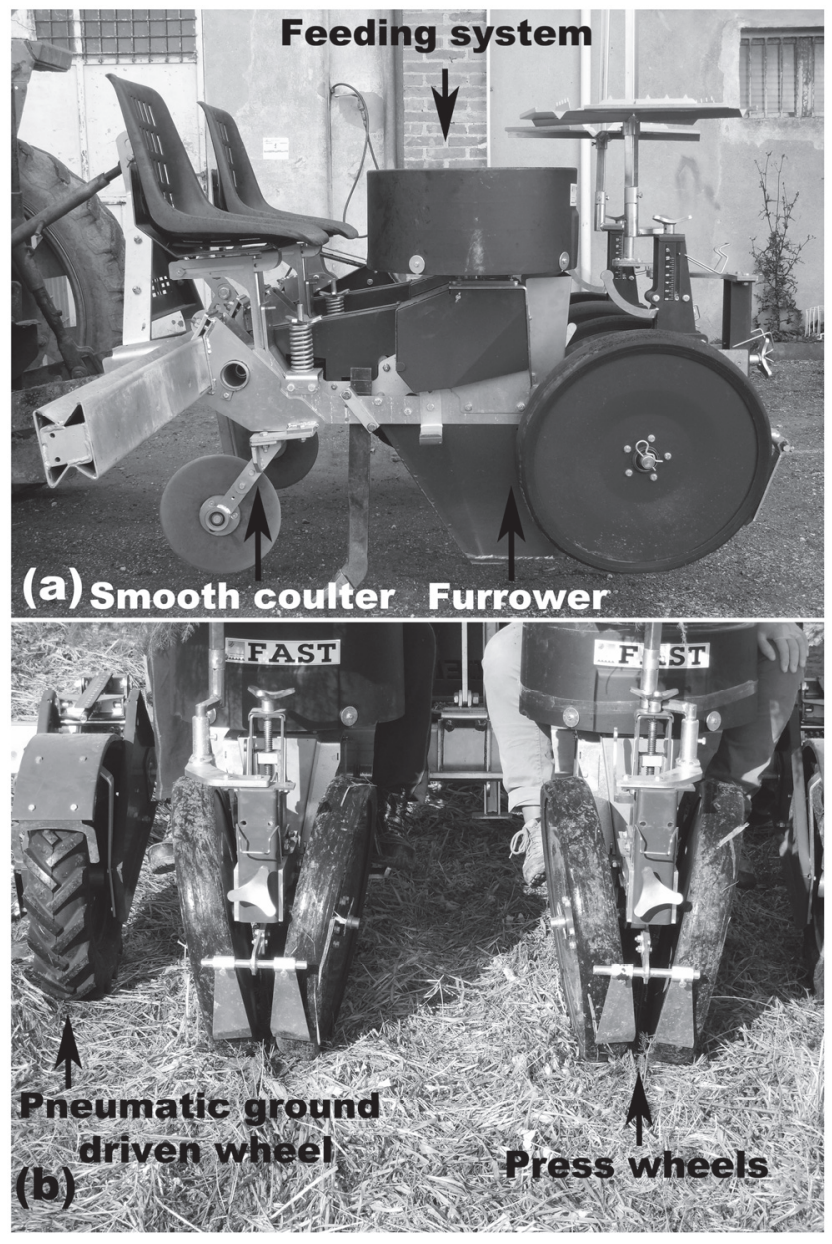

Figure 2. (a) Lateral and (b) rear views of vegetable transplanter. 


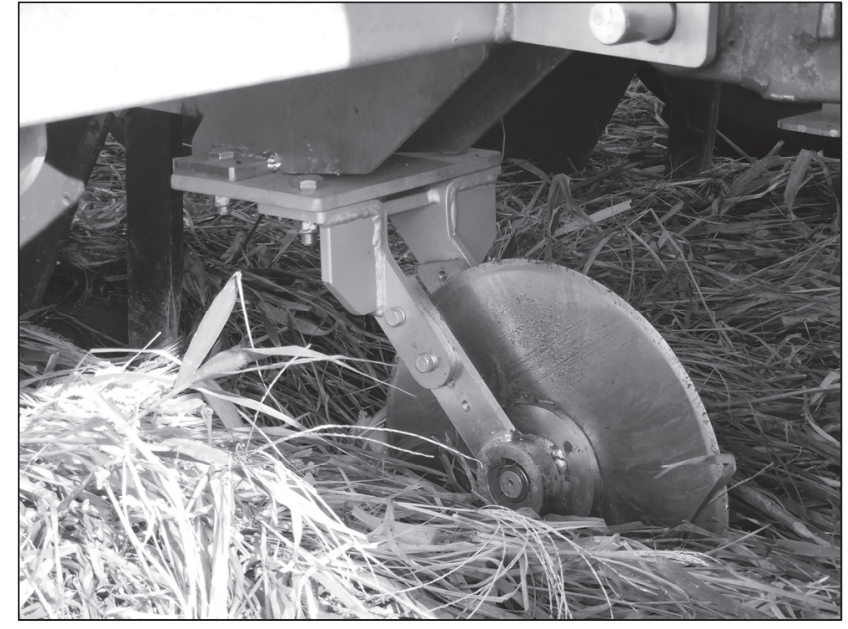

Figure 3. Smooth coulter, a flat disc with a sharpened edge.

the main frame (fig. 2a). The flat disc of the smooth coulter is $2.5 \mathrm{~mm}$ thick and is made of boron steel with a durable tungsten/cobalt lining. The smooth coulter cuts the cover crop residue and also cuts and loosens the soil up to $12 \mathrm{~cm}$ depth to enhance the performance of the components that follow. Different tools can be adopted for tilling or loosening a narrow band of soil before the passing of the furrower. These tools can be either chisel or ripper shank openers equipped with winged or straight nose points (fig. 4). The shanks, made of high-strength steel (Weldox 700), are $59 \mathrm{~cm}$ tall, $15 \mathrm{~mm}$ thick, and are mounted on the pivoting part of the transplanter in front of the furrower.

Figure 5 shows the measurements of the winged and (a)

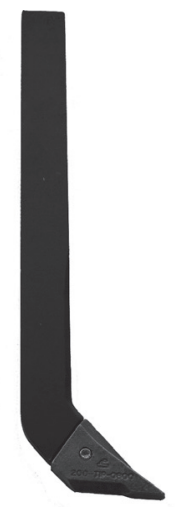

(c)

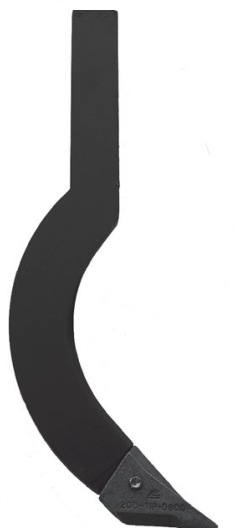

(b)

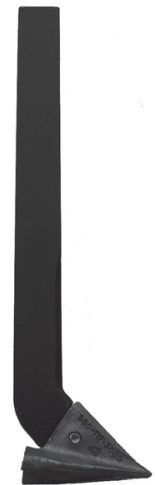

(d)

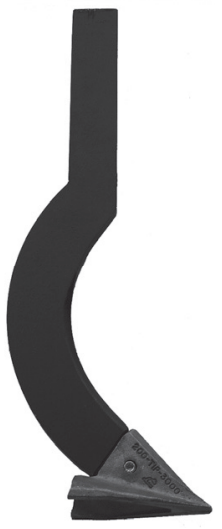

Figure 4. Different kinds of shank openers equipped with different points: (a) ripper shank opener with straight nose point, (b) ripper shank opener with winged point, (c) chisel shank opener with straight nose point, and (d) chisel shank opener with winged point.

(b)
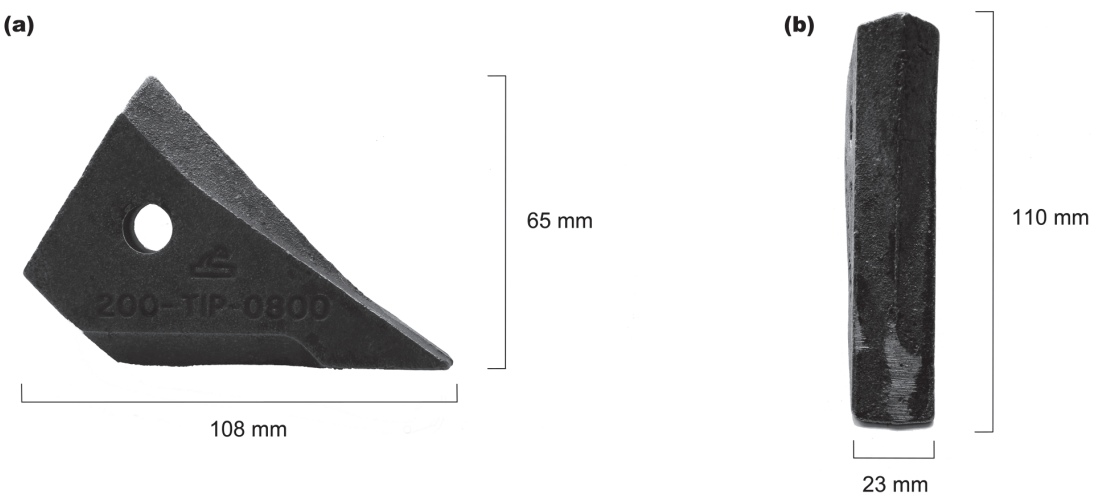

(c)

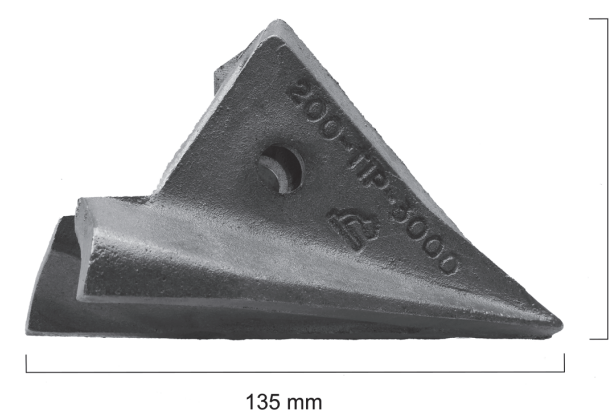

(d)

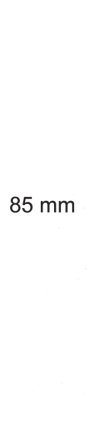

(d)

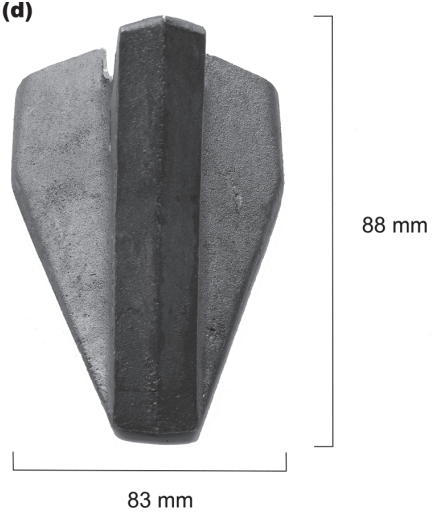

Figure 5. Different kinds of points with their corresponding dimensions: (a) lateral view of straight nose point, (b) top view of straight nose point, (c) lateral view of winged point, and (d) top view of winged point. 
straight nose points (produced by Bourgault Tillage Tools, Saskatchewan, Canada), which are made of Hi-Chrome abrasion-resistant iron ( $27 \%$ chrome). Both the smooth coulter and the tilling or loosening tools can be adjusted to till the soil at different depths. Their dimensions were designed to optimize the cutting of the soil while considering the reduced space available on the frame of the transplanter. The aim of equipping the transplanter with different combinations of openers and points was to make the machine suitable for working in different soil conditions. This is a requirement of conservation agriculture; to maximize the agronomic and environmental benefits, the cropping system and the machinery must be tailored to specific pedo-climatic conditions and to particular combinations of cash crop and cover crop. The use of openers is essential because they loosen the soil to allow proper establishment of the seedlings. The smooth coulter alone is not wide enough to create a sufficiently open furrow for optimal seedling establishment. Its function is mainly related to cutting the plant residue. Contrary to conventional tillage systems, where the soil is tilled before transplant, openers allow loosening of the soil together with the transplant operation. The total mass of the transplanter with three seedling transplant units for use in no-till soil is 648 $\mathrm{kg}$. With this configuration, the transplanter is $2.50 \mathrm{~m}$ wide and $1.45 \mathrm{~m}$ long.

\section{EXPERIMENTAL DESIGN AND TREATMENTS}

The draft force (i.e., the total force parallel to the direction of travel required to pull the transplanter) was measured in July 2016 at the experimental farm of the University of Pisa $\left(43.68^{\circ} \mathrm{N}, 10.33^{\circ} \mathrm{E}\right)$ in central Italy. The soil, based on the USDA soil classification system, was sandy loam $(67.0 \%$ sand, $17.5 \%$ clay, and $15.5 \%$ silt) with $2.1 \%$ organic matter. The field type was no-till and plain. The soil water content was $8 \%$, expressed as a percentage of wet soil weight. Before the draft force measurements, weeds in the field were chopped. The tractor forward speed was $1 \mathrm{~km} \mathrm{~h}^{-1}$, the working depth of the furrower was set to $8 \mathrm{~cm}$, and the depth of the smooth coulter was set to $10 \mathrm{~cm}$. The forward speed of $1 \mathrm{~km} \mathrm{~h}^{-1}$ was chosen because it allows the operators to comfortably drop plants into the cups even when the plant-toplant spacing is small (e.g., $20 \mathrm{~cm})$. The depth of the furrower was set to $8 \mathrm{~cm}$ because the seedling cell was $5 \mathrm{~cm}$ height, and a higher depth of the furrower would have involved an improperly deep deposition of the seedlings. The smooth coulter was set to $10 \mathrm{~cm}$ because cutting a deep layer of soil is required in no-till systems, which contain cover crop roots. The experimental design was a randomized complete-block design with three replications. The size of each plot was $30 \mathrm{~m}^{2}(1.5 \mathrm{~m} \times 20 \mathrm{~m})$. The treatments consisted of combinations of (1) the working depth of the shank opener $(13,16,19,22$, or $25 \mathrm{~cm})$; (2) the number of transplant units (one, two, or three); (3) the type of shank opener (chisel or ripper); and (4) the type of point (winged or straight nose), for a total of 60 treatments.

Field experiments to evaluate the transplanter accuracy and the transplant success rate were conducted in 2014, 2015, and 2016 at the experimental farm of the University of Pisa $\left(43.67^{\circ} \mathrm{N}, 10.34^{\circ} \mathrm{E}\right)$ in central Italy. Transplanter accuracy and transplant success rate were evaluated for savoy cabbage (Brassica oleracea L. var. sabauda, "Famosa" F1 hybrid), fennel (Foeniculum vulgare Mill. cv. "Montebianco"), and lettuce (Lactuca sativa L. var. capitata cv. "Ballerina"), which had a different spatial arrangement. Savoy cabbage was transplanted at the beginning of August, fennel at the end of August, and lettuce at the end of May. The field parameters for each crop are reported in table 1 . The soil, based on the USDA soil classification system, was loamy sand $(80.7 \%$ sand, $5.7 \%$ clay, and $13.6 \%$ silt $)$ with $2.3 \%$ organic matter.

In the tilled soil, a spading machine was used at $18 \mathrm{~cm}$ depth, one week before transplanting. In the no-till soil, fennel was transplanted on a dead mulch of a mixture of Fagopyrum esculentum (Moench), Vigna unguiculata (L.), Panicum miliaceum (L.), and Setaria italica (L.), which had been previously terminated with a roller-crimper and a flamer. Savoy cabbage and lettuce were transplanted on a living mulch of red clover (Trifolium pratense L.), which was chopped before transplanting. The transplanter was equipped with a chisel opener and winged point to transplant savoy cabbage and lettuce onto living mulch and to till the soil enough to give the crop a competitive advantage over the red clover. The ripper opener and straight nose point enabled the fennel to be transplanted on dead mulch, to keep the residue as uniform as possible.

The working depth of the shank openers was $16 \mathrm{~cm}$ for all crops. The working depth of the smooth coulter was set at $10 \mathrm{~cm}$. The working depth of the furrower was regulated at $8 \mathrm{~cm}$ in both the tilled and no-till soils. The water requirements, provided by sprinklers during the first 15 days of seedling establishment, were approximately 52, 55, and $70 \mathrm{~mm}$, respectively for fennel, savoy cabbage, and lettuce. The experimental design was a randomized complete-block design with three replications. The size of each plot was $63 \mathrm{~m}^{2}$ ( $3 \mathrm{~m}$ width $\times 21 \mathrm{~m}$ length). The treatments (i.e., transplants) were repeated for three years.

\section{Transplanter Performance AND DATA COLlection}

Transplanter performance was evaluated in terms of draft

Table 1. Field parameters of transplanter used for three vegetable crops during three-year experiment in tilled and no-till soils.

\begin{tabular}{|c|c|c|c|}
\hline \multirow[b]{2}{*}{ Parameter } & \multicolumn{3}{|c|}{ Crop } \\
\hline & Savoy Cabbage & Fennel & Lettuce \\
\hline Row spacing $(\mathrm{cm})$ & 75.00 & 75.00 & 50.00 \\
\hline Theoretical spacing $(\mathrm{cm})$ & 50.00 & 25.00 & 20.00 \\
\hline Forward speed $\left(\mathrm{km} \mathrm{h}^{-1}\right)$ & 2.35 & 1.14 & 0.94 \\
\hline Theoretical field capacity $\left(\right.$ ha $\left.h^{-1}\right)$ & 0.35 & 0.17 & 0.14 \\
\hline Seedling transplant units & Two & Two & Three \\
\hline Labor requirement per row & Two operators & Two operators & Three operators \\
\hline Hand-feeding rate (seedlings per row $\mathrm{s}^{-1}$ ) & 1.30 & 1.28 & 1.33 \\
\hline Soil water content ( $\%$ of wet soil weight) & 11.27 (tilled), 13.03 (no-till) & 11.63 (tilled), 15.44 (no-till) & 12.11 (tilled), 23.22 (no-till) \\
\hline
\end{tabular}


force, transplanter accuracy, and transplant success rate. No damage to seedling leaves or stems was observed after transplanting. The angle of an established seedling from a vertical line was always less than a $30^{\circ}$, as suggested by Manilla and Shaw (1987) for successful planting.

The draft force data were recorded using a dynamometer (TLP-100KNB, Tokyo Sokki Kenkyujo Co., Ltd., Tokyo, Japan) connected to an analog-digital signal converter, which sent data directly to a laptop computer. The data sampling rate was set at $1 \mathrm{~Hz}$, so draft force values were acquired every $1 \mathrm{~s}$. The dynamometer was connected between two tractors using chains and steel shackles according to the standard test procedure (RNAM, 1983). The transplanter was coupled to the three-point hitch of the rear towed tractor. The part of the force due to the rolling resistance of the towed tractor was subtracted from the total force registered. Before data analysis, means were calculated from the individual measurements by dividing by the time needed to run a total distance of $20 \mathrm{~m}$. The initial values when the draft force was unstable were also subtracted from the data.

Transplanter accuracy was evaluated in terms of: (1) multiple seedlings transplanted at the same time (multiple index); (2) failure of a seedling to be transplanted, i.e., one or more of the locations where a seedling should have been transplanted was skipped (miss index); (3) seedlings transplanted at the appropriate distance (quality of feed index); and (4) the variability in spacing between seedlings transplanted at the appropriate distance (precision). These measurements were based on the theoretical spacing for the transplanted crops. The theoretical spacing is the distance between the seedlings assuming no skips, multiples, or variability and is based on the optimal distance between crop plants in the row. For fennel, savoy cabbage, and lettuce, theoretical spacings of 25, 50, and $20 \mathrm{~cm}$, respectively, were used. Sample spacing was counted along a $10 \mathrm{~m}$ distance within transplanted lines in the middle of the plot (two for fennel and savoy cabbage, and three for lettuce) immediately after transplanting. The accuracy indexes were calculated following the method of Kachman and Smith (1995) for planters, which defines three regions where: (1) seedlings were transplanted at the same time and the percentage of spacings that were less than or equal to 0.50 of the theoretical spacing (multiple index); (2) seedlings had at least one single skip between them and the percentage of spacings greater than 1.50 times the theoretical spacing (miss index); and (3) seedlings were placed close to the theoretical spacing and the percentage of spacings that were greater than 0.50 but less than 1.50 times the theoretical spacing (quality of feed index). We decided to restrict by half the regions defined by Kachman and Smith (1995) because we assumed that a transplanter would be more precise than a planter. Thus, in this study, the multiple index was calculated as the percentage of spacings (referred to as plant-to-plant spacing) that were less than or equal to 0.75 of the theoretical spacing, the miss index was calculated as the percentage of spacings greater than 1.25 times the theoretical spacing, and the quality of feed index was calculated as the percentage of spacings that were greater than 0.75 but less than 1.25 times the theoretical spacing.
The transplant success rate was computed as the ratio between the successful plantings and the total number of seedlings dropped. The surviving seedlings were counted along a $10 \mathrm{~m}$ distance within the crop rows 14 days after transplant, taking care that only the transplanter performance had influenced the seedling establishment.

\section{Statistical Analysis}

Normality was tested using the Shapiro-Wilk normality test (Royston, 1995). A preliminary mixed analysis of variance (ANOVA) of the draft force (daN) was conducted with the extension package lmerTest (Kuznetsova et al., 2014) of R statistical software (R Core Team, 2013). The working depth of the shank opener, the number of transplant units, the type of shank opener, and the type of point were the fixed effects, and the replication was the random effect. Data were then modeled in a linear regression using Prism-GraphPad statistical software (Motulsky, 2016). The extra sum-of-squares F test, evaluating whether all the data sets could be modeled in one curve, was significant ( $p<0.0001)$. Thus, data were presented separately for the number of transplant units and combinations of shank opener and point. A test of lack-of-fit at the $95 \%$ level was not significant for any of the regression lines tested, indicating that the regression model was correct.

Data for the multiple index, miss index, and quality of feed index were logit transformed (an adjustment of \pm 0.005 was used due to the presence of one and zero values) and modeled in a linear mixed model using the lmerTest extension package of R (Kuznetsova et al., 2014). Precision data were distributed normally and were modeled directly in a linear mixed model using lmerTest (Kuznetsova et al., 2014). For all the indexes and precision, the condition of the soil (tilled and no-till), the operator performing the transplant (the same person for the same row in all three years), and the year were the fixed effects, and the block was the random effect.

The transplant success rate was modeled as a binomial proportion in a generalized linear mixed model using lmerTest (Kuznetsova et al., 2014), which conducted a logit transformation. The condition of the soil (tilled or no-till) and the year were the fixed effects, and replications nested in blocks were the random effects. The mixed ANOVA was computed using the extension package afex (analysis of factorial experiments) of R (Singmann et al., 2016).

Non-significant fixed effects and interactions were excluded from the models. The extension package lsmeans (least-squares means) of R (Russell and Hervé, 2015) was used to compute the least-squares means and standard errors of dependent variables and the inverse-transformed values of logit-transformed data in the mixed models.

Comparisons between least-squares means were computed considering a $95 \%$ confidence interval (CI) of the difference between the means of two groups. If the resulting $95 \%$ CI of the difference between means did not cross a value of zero 0 , then the null hypothesis (that the compared means were equal) was rejected. The CI for the difference between two group means was computed using equation 1 (Knezevic, 2008):

$\mathrm{CI}($ difference $)=\left(x_{1}-x_{2}\right) \pm 1.96 \sqrt{\left(\mathrm{SE}_{x_{1}}\right)^{2}+\left(\mathrm{SE}_{x_{2}}\right)^{2}}$ 
where $\mathrm{CI}$ is the confidence interval for the difference, $x_{1}$ is the value of the first least-squares mean, $x_{2}$ is the value of the second least-squares mean, $\mathrm{SE}$ is the standard error of $x_{1}$ and $x_{2}$, respectively, and 1.96 is the critical t-value.

\section{RESULTS}

The mixed ANOVA showed that the draft force (daN) was influenced by the working depth of the shank opener, the number of transplant units, the type of shank opener, the type of point, and almost all the interactions. The p-values are reported in table 2. For each number of seedling transplant units, the regression analysis showed that the combination of the ripper shank opener with straight nose point always gave the low-

Table 2. Significance (5\% level) in mixed ANOVA of the effects of shank opener working depth (WD; 13, 16, 19, 22, or $25 \mathrm{~cm}$ ), number of transplant units (TU; one, two, or three), type of shank opener (SO; chisel or ripper), type of point (TP; winged or straight nose), and their interactions on draft force.

\begin{tabular}{ccc}
\hline Variable & Term & $\mathrm{p}$-Value \\
\hline Draft force $(\mathrm{daN})$ & $\mathrm{WD}$ & $<0.0001$ \\
$\mathrm{TU}$ & $<0.0001$ \\
SO & $<0.0001$ \\
TP & $<0.0001$ \\
$\mathrm{WD} \times \mathrm{TU}$ & $<0.0001$ \\
$\mathrm{WD} \times \mathrm{SO}$ & $<0.0001$ \\
$\mathrm{TU} \times \mathrm{SO}$ & $<0.0001$ \\
$\mathrm{WD} \times \mathrm{TP}$ & $<0.0001$ \\
$\mathrm{TU} \times \mathrm{TP}$ & $<0.0001$ \\
$\mathrm{SO} \times \mathrm{TP}$ & $<0.0001$ \\
$\mathrm{WD} \times \mathrm{TU} \times \mathrm{SO}$ & 0.0016 \\
$\mathrm{WD} \times \mathrm{TU} \times \mathrm{TP}$ & 0.0333 \\
$\mathrm{WD} \times \mathrm{SO} \times \mathrm{TP}$ & 0.0033 \\
$\mathrm{TU} \times \mathrm{SO} \times \mathrm{TP}$ & $<0.0001$ \\
$\mathrm{WD} \times \mathrm{TU} \times \mathrm{SO} \times \mathrm{TP}$ & 0.8249 \\
\hline
\end{tabular}

est draft force values per unit of working depth $\left(\mathrm{daN} \mathrm{cm}^{-1}\right)$ (slope of the line) when two or three transplant units were used (table 3). When only one transplant unit was used, the ripper shank opener with straight nose point led to a similar draft force as the ripper shank opener with winged point $(95 \% \mathrm{CI}$ : $-4.13,0.41)$. The chisel shank opener with winged point always gave the highest draft force values per unit of working depth $\left(\mathrm{daN} \mathrm{cm}{ }^{-1}\right)$ when two or three transplant units were used (table 3). When only one transplant unit was used, the chisel shank opener with straight nose point led to a similar draft force as the chisel shank opener with winged point (95\% CI: $0.65,2.35)$. With the same number of transplant units, the combinations of ripper shank opener with winged point and chisel shank opener with straight nose point resulted in the same draft force values per unit of working depth $\left(\mathrm{daN} \mathrm{cm}^{-1}\right)$ $(95 \%$ CIs $=-3.24,0.50 ;-3.82,1.28$; and $-6.72,1.40$, with one, two, or three transplant units, respectively). The $\mathrm{r}^{2}$ values of the regressions are shown in figure 6.

The intercept parameter is the estimated draft force (daN) due to the rolling resistance of the transplanter, the furrower, and the smooth coulter, without the shank opener. These intercept values were similar for each combination of opener and point tested for the same number of transplant units. With an increasing number of transplant units, the intercept values increased significantly for all combinations of opener and point. The slopes and intercepts are presented in table 3 .

Table 4 reports the p-values resulting from the ANOVA for transplanter accuracy. The operator factor was always not significant for the three indexes (multiple, miss, and quality of feed) and the precision at all theoretical spacings (table 4), suggesting that each operator worked in a similar way. At a theoretical spacing of $25 \mathrm{~cm}$ (fennel), the only sig-

Table 3. Slopes and intercepts for different regressions lines estimated for different combinations of shank opener and point for an increasing number of transplant units. Standard errors are shown in parentheses. Regression lines are plotted in figure 6.

\begin{tabular}{|c|c|c|c|c|c|c|}
\hline \multirow[b]{2}{*}{ Opener and Point Combination } & \multicolumn{3}{|c|}{ Slope $\left(\mathrm{daN} \mathrm{cm} \mathrm{cm}^{-1}\right)( \pm \mathrm{SE})$} & \multicolumn{3}{|c|}{ Intercept $(\mathrm{daN})( \pm \mathrm{SE})$} \\
\hline & One Unit & Two Units & Three Units & One Unit & Two Units & Three Units \\
\hline Ripper shank opener and straight nose & $15.11(0.97)$ & $30.19(1.46)$ & $43.76(1.19)$ & $114.40(18.88)$ & $226.90(28.40)$ & $352.40(23.25)$ \\
\hline Ripper shank opener and winged point & $16.97(0.64)$ & $34.96(0.89)$ & $50.30(1.48)$ & $117.00(12.39)$ & $211.30(17.39)$ & $356.60(28.89)$ \\
\hline Chisel shank opener and straight nose point & $18.34(0.71)$ & $36.23(0.94)$ & $52.96(1.44)$ & $109.70(13.79)$ & $219.60(18.37)$ & $356.80(28.07)$ \\
\hline Chisel shank opener and winged point & $19.19(0.29)$ & $38.58(0.72)$ & $57.07(1.07)$ & $111.10(5.72)$ & $220.70(14.05)$ & $337.10(20.74)$ \\
\hline
\end{tabular}

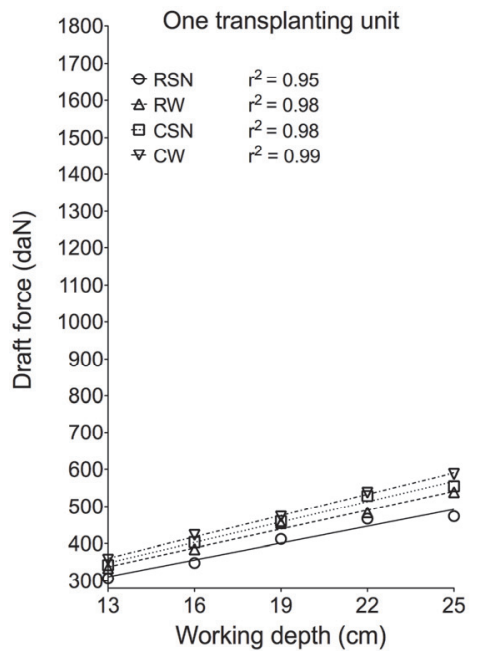

(a)

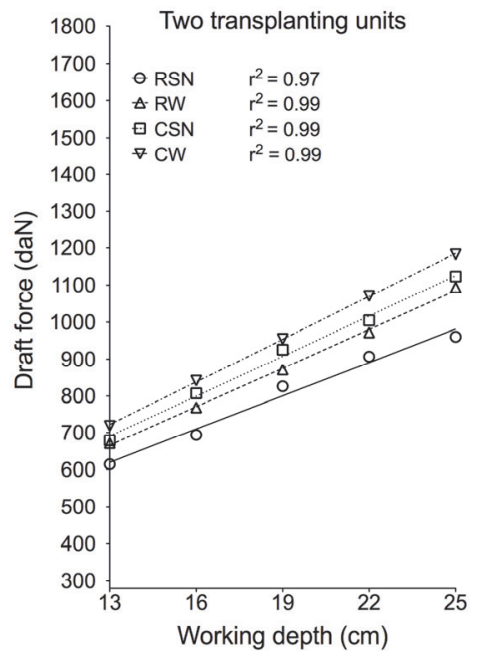

(b)

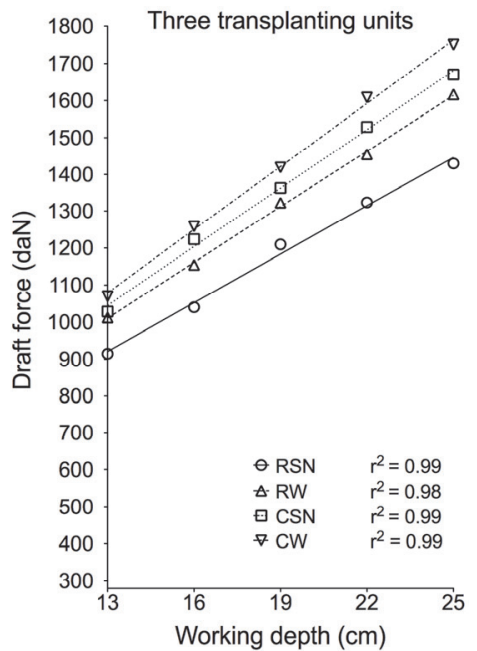

(c)

Figure 6. Regression lines estimated for different combinations of shank opener and point using (a) one, (b) two, or (c) three transplant units at different depths of the shank opener. The $r^{2}$ values of the regressions are also shown. 
Table 4. Significance (5\% level) in mixed ANOVA of the effects of soil condition (SC; tilled or no-till), number of operators (O; two for savoy cabbage and fennel, three for lettuce), year (Y; 2014, 2015, or 2016), and their interactions on multiple index, miss index, quality of feed index, and precision at three theoretical spacings (TS).

\begin{tabular}{|c|c|c|c|}
\hline \multirow{2}{*}{ Variable and Term } & \multicolumn{3}{|c|}{ p-Value } \\
\hline & $\mathrm{TS}=50 \mathrm{~cm}$ & $\mathrm{TS}=25 \mathrm{~cm}$ & $\mathrm{TS}=20 \mathrm{~cm}$ \\
\hline \multicolumn{4}{|l|}{ Multiple index } \\
\hline $\mathrm{SC}$ & 0.0569 & 0.9848 & 0.2996 \\
\hline $\mathrm{O}$ & 0.3273 & 0.9120 & 0.7151 \\
\hline $\mathrm{Y}$ & 0.0687 & $<0.0001$ & 0.0011 \\
\hline $\mathrm{SC} \times \mathrm{O}$ & 1.0000 & 0.5784 & 0.9881 \\
\hline $\mathrm{SC} \times \mathrm{Y}$ & 0.0317 & 0.6053 & 0.1054 \\
\hline $\mathrm{O} \times \mathrm{Y}$ & 0.3827 & 0.0976 & 0.3545 \\
\hline $\mathrm{SC} \times \mathrm{O} \times \mathrm{Y}$ & 1.0000 & 0.2612 & 0.7992 \\
\hline \multicolumn{4}{|l|}{ Miss index } \\
\hline $\mathrm{SC}$ & 0.0011 & 0.3371 & 0.0026 \\
\hline $\mathrm{O}$ & 0.1113 & 0.6735 & 0.4249 \\
\hline $\mathrm{Y}$ & $<0.0001$ & 0.0050 & $<0.0001$ \\
\hline $\mathrm{SC} \times \mathrm{O}$ & 0.5675 & 0.6735 & 0.6034 \\
\hline $\mathrm{SC} \times \mathrm{Y}$ & 0.0001 & 0.5292 & 0.0228 \\
\hline $\mathrm{O} \times \mathrm{Y}$ & 0.4054 & 0.6908 & 0.7768 \\
\hline $\mathrm{SC} \times \mathrm{O} \times \mathrm{Y}$ & 0.7175 & 0.3319 & 0.7767 \\
\hline \multicolumn{4}{|l|}{ Quality of feed index } \\
\hline $\mathrm{SC}$ & 0.0005 & 0.3055 & 0.0051 \\
\hline $\mathrm{O}$ & 0.0592 & 0.4516 & 0.6432 \\
\hline $\mathrm{Y}$ & $<0.0001$ & $<0.0001$ & $<0.0001$ \\
\hline $\mathrm{SC} \times \mathrm{O}$ & 0.9014 & 0.7537 & 0.5499 \\
\hline $\mathrm{SC} \times \mathrm{Y}$ & 0.0002 & 0.3265 & 0.0349 \\
\hline $\mathrm{O} \times \mathrm{Y}$ & 0.1468 & 0.3690 & 0.5766 \\
\hline $\mathrm{SC} \times \mathrm{O} \times \mathrm{Y}$ & 0.5928 & 0.2310 & 1.0000 \\
\hline \multicolumn{4}{|l|}{ Precision } \\
\hline $\mathrm{SC}$ & 0.0031 & 0.3994 & 0.0714 \\
\hline $\mathrm{O}$ & 0.7725 & 0.6511 & 0.2237 \\
\hline $\mathrm{Y}$ & $<0.0001$ & $<0.0001$ & $<0.0001$ \\
\hline $\mathrm{SC} \times \mathrm{O}$ & 0.2155 & 0.1379 & 0.3870 \\
\hline $\mathrm{SC} \times \mathrm{Y}$ & 0.0075 & 0.3501 & 0.0299 \\
\hline $\mathrm{O} \times \mathrm{Y}$ & 0.3596 & 0.1693 & 0.5437 \\
\hline $\mathrm{SC} \times \mathrm{O} \times \mathrm{Y}$ & 0.2036 & 0.2654 & 0.0329 \\
\hline
\end{tabular}

nificant factor was the year (table 4), suggesting that there were no differences between the indexes and the precision in the tilled and no-till soils. When the theoretical spacings were 50 or $20 \mathrm{~cm}$ (savoy cabbage and lettuce, respectively), the soil condition (tilled or no-till), year, and their interaction were significant for at least one index (table 4). Thus, the subsequent least-squares means data are presented separately for each year and soil condition.
The multiple index was $0 \%$ or close to $0 \%$ for all theoretical spacings and years (tables 5, 6, and 7). This suggests that the transplanter did not transplant seedlings at the same time in both the tilled and no-till soils (the percentage of spacings that were less than or equal to 0.75 of the theoretical spacing was $0 \%$ or close to $0 \%$ ).

The miss index was $0 \%$ or close to $0 \%$ when seedlings were transplanted at theoretical spacings of 50 and $25 \mathrm{~cm}$ (tables 5 and 6). When the theoretical spacing was reduced to $20 \mathrm{~cm}$, the transplanter sometimes failed to maintain the desired spacing (possibly due to higher seeding rates being planted), and these failures were generally higher in the tilled soil (table 7). When seedlings were transplanted at theoretical spacings of 50 and $25 \mathrm{~cm}$, the quality of feed index was $100 \%$ or close to this value (tables 5 and 6 ), whereas at the theoretical spacing of $20 \mathrm{~cm}$, the quality of feed index decreased to less than $100 \%$ (table 7 ), which could be attributed to the large number of skips in both the tilled and no-till soils. These occurrences were higher in 2014, when the miss index reached $30 \%$ and the quality of feed index reached $70 \%$.

The precision values are also reported in tables 5, 6, and 7. When the theoretical spacing was $50 \mathrm{~cm}$, the highest estimated precision over the three years for both types of soil was $11 \%( \pm 0.7 \%)$, and the maximum standard deviation was $50 \mathrm{~cm} \times 11 \%+(1.96 \times 0.7 \%)=5.5 \mathrm{~cm}$. This means that when seedlings were transplanted within the target range (i.e., after removing multiples and skips), the maximum deviation from the theoretical spacing was $\pm 5.5 \mathrm{~cm}$. The minimum estimated deviation was $\pm 1.5 \mathrm{~cm}$ in 2015 in the no-till soil. When the theoretical spacing was $25 \mathrm{~cm}$, the maximum deviation from the theoretical spacing was $\pm 3.3 \mathrm{~cm}$, and the minimum was $\pm 1.8 \mathrm{~cm}$. When the theoretical spacing was $20 \mathrm{~cm}$, the maximum deviation from the theoretical spacing was $\pm 2.6 \mathrm{~cm}$, and the minimum was $\pm 1.4 \mathrm{~cm}$.

The transplant success rate was similar in all years $(\mathrm{p}=$ $0.95,0.25$, and 0.53 for lettuce, savoy cabbage, and fennel, respectively). The interaction of soil condition and year was also not significant $(\mathrm{p}=0.19,0.07$, and 0.53 for lettuce, savoy cabbage, and fennel, respectively); thus, the data were pooled over years. ANOVA showed that the number of surviving lettuce seedlings at 14 days after transplanting was

Table 5. Transplanter accuracy evaluated in terms of multiple, miss, and quality of feed indexes and precision reported as least-squares means (Lsmean) and standard error (SE) in tilled and no-till soils for savoy cabbage at theoretical spacing of $50 \mathrm{~cm}$ in 2014,2015 , and 2016.

\begin{tabular}{|c|c|c|c|c|c|}
\hline \multirow[b]{2}{*}{ Year } & \multirow[b]{2}{*}{ Variable $^{[\mathrm{a}]}$} & \multicolumn{2}{|c|}{ Lsmean $( \pm \mathrm{SE})$} & \multicolumn{2}{|c|}{ Inverse-Transformed Value $( \pm \mathrm{SE})(\%)$} \\
\hline & & Tilled & No-till & Tilled & No-till \\
\hline \multirow[t]{4}{*}{2014} & Multiple index & $-5.29(0.33)$ & $-5.29(0.33)$ & $0.00(0.00)$ & $0.00(0.00)$ \\
\hline & Miss index & $-5.29(0.32)$ & $-5.29(0.32)$ & $0.00(0.00)$ & $0.00(0.00)$ \\
\hline & Quality of feed index & $5.29(0.37)$ & $5.29(0.37)$ & $100.00(0.00)$ & $100.00(0.00)$ \\
\hline & Precision & $10.65(0.74)$ & $11.43(0.74)$ & - & - \\
\hline \multirow[t]{4}{*}{2015} & Multiple index & $-4.87(0.33)$ & $-4.87(0.33)$ & $0.26(0.09)$ & $0.26(0.09)$ \\
\hline & Miss index & $-4.87(0.32)$ & $-4.87(0.32)$ & $0.26(0.08)$ & $0.26(0.08)$ \\
\hline & Quality of feed index & $4.44(0.37)$ & $4.75(0.37)$ & $99.33(0.24)$ & $99.64(0.13)$ \\
\hline & Precision & $5.92(0.74)$ & $3.49(0.74)$ & - & - \\
\hline \multirow[t]{4}{*}{2016} & Multiple index & $-3.59(0.33)$ & $-5.29(0.33)$ & $2.19(0.71)$ & $0.00(0.00)$ \\
\hline & Miss index & $-2.01(0.32)$ & $-4.87(0.32)$ & $11.32(3.21)$ & $0.26(0.08)$ \\
\hline & Quality of feed index & $1.74(0.37)$ & $4.87(0.37)$ & $85.57(4.57)$ & $99.74(0.10)$ \\
\hline & Precision & $11.47(0.74)$ & $7.43(0.74)$ & - & - \\
\hline
\end{tabular}

Multiple index = percentage of seedlings that were transplanted at the same time as the previous seedling.

Miss index = percentage of seedlings that had at least one single skip between them.

Quality of feed index = percentage of spacings between seedlings that were close to theoretical spacing $(50 \mathrm{~cm})$.

Precision $=$ percentage variability in spacing between seedlings transplanted close to theoretical $\mathrm{spacing}(50 \mathrm{~cm})$. 
Table 6. Transplanter accuracy evaluated in terms of multiple, miss, and quality of feed indexes and precision reported as least-squares means (Lsmean) and standard error (SE) for fennel at theoretical spacing of $25 \mathrm{~cm}$ in 2014, 2015, and 2016.

\begin{tabular}{|c|c|c|c|c|c|c|}
\hline \multirow[b]{2}{*}{ Variable $^{[a]}$} & \multicolumn{2}{|c|}{2014} & \multicolumn{2}{|c|}{2015} & \multicolumn{2}{|c|}{2016} \\
\hline & $\begin{array}{c}\text { Lsmean } \\
( \pm \text { SE })\end{array}$ & $\begin{array}{c}\text { Inverse- } \\
\text { Transformed } \\
\text { Value } \\
(\%)( \pm \mathrm{SE})\end{array}$ & $\begin{array}{c}\text { Lsmean } \\
( \pm \mathrm{SE})\end{array}$ & $\begin{array}{c}\text { Inverse- } \\
\text { Transformed } \\
\text { Value } \\
(\%)( \pm \mathrm{SE})\end{array}$ & $\begin{array}{c}\text { Lsmean } \\
( \pm \mathrm{SE})\end{array}$ & $\begin{array}{c}\text { Inverse- } \\
\text { Transformed } \\
\text { Value } \\
(\%)( \pm \mathrm{SE})\end{array}$ \\
\hline Multiple index & $-2.49(0.28)$ & $7.16(1.86)$ & $-3.99(0.28)$ & $1.32(0.36)$ & $-5.13(0.28)$ & $0.09(0.02)$ \\
\hline Miss index & $-5.29(0.25)$ & $0.00(0.00)$ & $-3.99(0.25)$ & $1.32(0.32)$ & $-4.92(0.25)$ & $0.22(0.06)$ \\
\hline Quality of feed index & $2.49(0.34)$ & $92.84(2.26)$ & $3.34(0.34)$ & $97.08(0.96)$ & $4.87(0.34)$ & $99.74(0.09)$ \\
\hline Precision & $12.66(0.44)$ & - & $9.27(0.44)$ & - & $7.15(0.44)$ & - \\
\hline
\end{tabular}

[a] Multiple index $=$ percentage of seedlings that were transplanted at the same time as the previous seedling.

Miss index $=$ percentage of seedlings that had at least one single skip between them.

Quality of feed index = percentage of spacings between seedlings that were close to theoretical spacing $(25 \mathrm{~cm})$.

Precision $=$ percentage variability in spacing between seedlings transplanted close to theoretical spacing $(25 \mathrm{~cm})$.

Table 7. Transplanter accuracy evaluated in terms of multiple, miss, and quality of feed indexes and precision reported as least-squares means (Lsmean) and standard error (SE) for lettuce in tilled and no-till soils at theoretical spacing of $20 \mathrm{~cm}$ in 2014, 2015 , and 2016.

\begin{tabular}{|c|c|c|c|c|c|}
\hline \multirow[b]{2}{*}{ Year } & \multirow[b]{2}{*}{ Variable $^{[\mathrm{a}]}$} & \multicolumn{2}{|c|}{ Lsmean $( \pm \mathrm{SE})$} & \multicolumn{2}{|c|}{ Inverse-Transformed Value $(\%)( \pm \mathrm{SE})$} \\
\hline & & Tilled & No-Till & Tilled & No-Till \\
\hline \multirow[t]{4}{*}{2014} & Multiple index & $-5.29(0.18)$ & $-5.29(0.18)$ & $0.00(0.00)$ & $0.00(0.00)$ \\
\hline & Miss index & $-0.79(0.25)$ & $-1.00(0.25)$ & $30.72(5.41)$ & $26.39(4.93)$ \\
\hline & Quality of feed index & $0.79(0.26)$ & $1.00(0.26)$ & $69.28(5.45)$ & $73.61(4.97)$ \\
\hline & Precision & $13.29(0.47)$ & $13.49(0.47)$ & - & - \\
\hline \multirow[t]{4}{*}{2015} & Multiple index & $-4.25(0.18)$ & $-4.25(0.18)$ & $0.91(0.16)$ & $0.91(0.16)$ \\
\hline & Miss index & $-1.97(0.25)$ & $-3.62(0.25)$ & $11.74(2.63)$ & $2.11(0.52)$ \\
\hline & Quality of feed index & $1.77(0.26)$ & $3.32(0.26)$ & $85.95(3.09)$ & $97.01(0.74)$ \\
\hline & Precision & $9.78(0.47)$ & $9.54(0.47)$ & - & - \\
\hline \multirow[t]{4}{*}{2016} & Multiple index & $-4.59(0.18)$ & $-4.59(0.18)$ & $0.51(0.09)$ & $0.51(0.09)$ \\
\hline & Miss index & $-3.15(0.25)$ & $-3.48(0.25)$ & $3.61(0.88)$ & $2.49(0.62)$ \\
\hline & Quality of feed index & $3.00(0.26)$ & $3.28(0.26)$ & $95.76(1.04)$ & $96.87(0.78)$ \\
\hline & Precision & $7.17(0.47)$ & $8.86(0.47)$ & - & - \\
\hline
\end{tabular}

[a] Multiple index $=$ percentage of seedlings that were transplanted at the same time as the previous seedling.

Miss index $=$ percentage of seedlings that had at least one single skip between them.

Quality of feed index = percentage of spacings between seedlings that were close to theoretical spacing $(20 \mathrm{~cm})$.

Precision $=$ percentage variability in spacing between seedlings transplanted close to theoretical spacing $(20 \mathrm{~cm})$.

Table 8. Transplant success rate computed as the ratio between successful transplants and total number of dropped seedlings counted 14 days after transplanting in tilled and no-till soils.

\begin{tabular}{|c|c|c|c|c|}
\hline \multirow[b]{2}{*}{ Crop } & \multicolumn{2}{|c|}{ Lsmean $( \pm \mathrm{SE})$} & \multicolumn{2}{|c|}{ Inverse-Transformed Value $(\%)( \pm \mathrm{SE})$} \\
\hline & Tilled & No-Till & Tilled & No-Till \\
\hline Lettuce & $2.95(0.24)$ & $3.69(0.25)$ & $95.03(1.13)$ & $97.56(0.59)$ \\
\hline Savoy cabbage & $3.94(0.32)$ & $4.19(0.35)$ & $98.09(0.60)$ & $98.51(0.51)$ \\
\hline Fennel & $3.82(0.29)$ & $3.54(0.27)$ & $97.85(0.61)$ & $97.18(0.74)$ \\
\hline
\end{tabular}

higher in the no-till soil $(\mathrm{p}=0.0001)$, highlighting a higher transplant success rate in the no-till soil of about $3 \%$ (table 8). For savoy cabbage and fennel seedlings, there were no differences between the transplant success rates in tilled and no-till soils $(\mathrm{p}=0.53$ and 0.32 , respectively, for savoy cabbage and fennel), which were not less than $97 \%$ (table 8). There were no statistical differences in transplant success rate between the opener used for fennel (ripper shank and straight nose point) compared to the opener used for lettuce and savoy cabbage (chisel shank and winged point) $(95 \%$ CIs $=-1.51,0.21$ and $-0.88,0.58$, respectively).

\section{DISCUSSION}

In general, the transplanter's performance in the no-till soil was similar to the performance in the tilled soil. This suggests that the modifications made in order to transplant in the no-till soil were adequate. The combinations of the shank openers and points made the transplanter suitable for working in variable no-till soil conditions with different kinds of cover crop management (e.g., dead mulch or living mulch). Morse et al. (1993) described a commercial trans- planter for no-till soils that had substantial differences compared to the transplanter described in this article. Their transplanter was equipped with a vertical pocket-type feeding system instead of a horizontal carousel rotary cup. Using a transplanter with a horizontal carousel rotary cup (instead of a vertical descending cup or pocket-type feeding system) allows the operators to place several seedlings rapidly and then allows a brief time to untangle seedlings or remove seedlings from cells, rather than having to maintain the exact timing for each seedling (Parish, 2005).

The general observation concerning the draft force measured to characterize the no-till transplanter was that the drive power requirement was very low $(8.8 \mathrm{~kW}$ with the ripper shank opener and straight nose point, and $10.8 \mathrm{~kW}$ with the chisel shank opener and winged point), indicating that the choice of tractor must be based on the lift capacity needed to support the weight of the transplanter. The draft force was influenced by the combination of shank opener and point, which increased from the ripper shank opener with straight nose point (less draft force) to the chisel shank opener with winged point (high draft force). This was probably due to the increase in the soil-working surfaces of tools from the ripper 
shank opener with straight nose point to the chisel shank opener with winged point (fig. 5). This tendency was more observable when two or three transplant units were used, compared to one transplant unit, because the differences in the soil-working surfaces increased with an increasing number of working tools. Al-Janobi et al. (2002) and Harrigan and Rotz (1994) also found an increase in draft force when a chisel shank was used, compared to less curved shanks.

The accuracy of the transplanter is an important factor in evaluating the transplanter performance (Kachman and Smith, 1995). The quality of feed index was nearly $100 \%$ for all theoretical spacings tested $(50,25$, and $20 \mathrm{~cm}$, respectively, for transplanting cabbage, fennel, and lettuce) in both the tilled and no-till soils, suggesting that the transplanter worked effectively overall. The exception observed at the theoretical spacing of $20 \mathrm{~cm}$ in 2014 (lettuce), where the quality of feed index was $74 \%$ and $69 \%$ in no-till and till soil, respectively, was probably due to the morphological characteristics of the seedlings, which could get stuck in the rotary cups if their epigeal structure was too developed. There were no significant problems due to the percentage of seedlings that were transplanted at the same time as the previous seedling (multiple index) for all theoretical spacings tested. This means that the total number of seedlings that were not close to the right transplant distance was mostly due to seedlings that had at least one single skip between them (miss index).

The higher miss indexes estimated in some cases, particularly at the theoretical spacing of $20 \mathrm{~cm}$, were probably due to the forward speed used, resulting in a feeding rate of 1.3 seedlings per row $\mathrm{s}^{-1}$. This rate could be too high, considering that Brewer (1997) reported that an operator seemed unable to feed seedlings much faster than one seedling per second without making errors (plant skips). The non-significance of the operator factor means that each operator worked in a similar way throughout the whole period of the study, irrespective of the soil condition and at all theoretical spacings (table 4). This does not rule out the fact that the operators may have encountered the same difficulties during transplanting, and this may explain the estimated percentages of missing seedlings. The morphological conformation of the seedlings could have affected the time required for the operator to pick up and entangle seedlings from the tray and transfer them to the cups. This could lead to a discordance between the real and desirable feeding rates at the pre-determined forward speed, which was relatively high. Zamani (2015) found that increasing the forward speed of an automatic vegetable transplanter for tilled soils significantly increased the distance between the seedlings in the row. This is because an increase in forward speed may lead to an increase in the operating rate of the automatic transplant mechanism, which may reduce the accuracy due to the lack of sufficient time to perform each task. This problem could also occur with human operators if the forward speed is too high.

The precision was higher at the theoretical spacing of $20 \mathrm{~cm}$, probably as a consequence of the smaller opportunity to count dropped seedlings far from the center of the theoretical spacing (i.e., $\pm 5 \mathrm{~cm}$ from the drop point), which was shorter than the theoretical spacings of 25 and $50 \mathrm{~cm}$ (i.e., \pm 6.25 and $\pm 12.5 \mathrm{~cm}$ from the drop point, respectively).

The transplant success rate was high for all seedling types. The lack of difference between the transplant success rates for savoy cabbage and fennel in the tilled and no-till soils suggests that the furrows were probably well formed, and the adjustable press wheels were able to successfully close the furrows in no-till conditions. The 3\% higher transplant success rate observed for lettuce in the no-till soil was probably due to a higher level of soil moisture in May compared to the tilled soil and was probably linked to possible humidity under the leaves of the living mulch. However, we do not have enough data to confirm this hypothesis.

A desired seedling stand and uniform crop growth were obtained in both the tilled and no-till soils. This suggests that the modifications to the transplanter also made it suitable to work effectively in the presence of living or dead mulch. The main technical obstacles to the establishment of no-till vegetable cropping systems in organic farming are non-chemical weed control and the thick layer of plant residue on the soil surface (Morse, 1999). The ability of this transplanter to operate effectively in no-till soil covered by either living or dead mulches makes this machine suitable for use by organic vegetable growers who adopt no-till in combination with cover crops in order to suppress weeds and supply nutrients to the cash crops. In organic farming, the management of cover crops and weeds without the use of herbicides also requires the use of other machines, such as roller crimpers and/or flamers, to achieve uniformly distributed, high-residue mulch in which directly transplanted cash crops can grow without excessive competition from other plants.

\section{Conclusions}

The transplanter described in this article offers a satisfactory technical solution for transplanting vegetables in both tilled and no-till soils with different types of cover crops. The draft force values per unit of working depth were lower when the combination of a ripper shank opener with a straight nose point was used, which makes this combination more suitable for transplanting in no-till soils due to the low power requirement. The transplant units were capable of placing seedlings at the appropriate theoretical spacing (within $\pm 13 \%$ ). The high transplant success rate $(95 \%$ to 99\%) ensured correct establishment of the seedlings, which resulted in less than $30^{\circ}$ inclination of the seedlings in wellformed furrows. Further studies could integrate the transplanter with an automatic feeding system to increase the speed of the transplant operation compared with the current hand-feeding rate, and consequently improve the field capacity and reduce operating costs. The transplanter could also be equipped with a system for supplying nutrients during planting. This would be an important improvement, especially for no-till transplanting in cropping systems where fertigation is not practiced, and thus top-dressing fertilization is not possible, with strong limitations for crop growth due to the reduced mineralization rate in no-till soils.

\section{ACKNOWLEDGEMENTS}

This work was supported by the Italian Ministry of Uni- 
versity and Research (MIUR) under the project "Integration and comparison of innovative technical approaches with different 'ecological intensification' finalized to a smart management of conservative agricultural systems." (Project Code RBFR13L8J6). The authors would like to thank the staff of the CiRAA "E. Avanzi" (University of Pisa) for their contribution to the management of the field experiments.

\section{REFERENCES}

Al-Janobi, A. A., Wahby, M. F., Aboukarima, A. M., \& Al-Hamed, S. A. (2002). Influence of chisel plow shank shape on horizontal and vertical force requirements. Agric. Sci., 7(1), 13-19. https://doi.org/10.24200/jams.vol7iss1pp13-19

Brewer, H. L. (1997). Increasing planting rates of gravity-fed field seedling transplanters. J. Veg. Crop Prod., 3(1), 3-19. https://doi.org/10.1300/J068v03n01_02

Calegari, A., Tiecher, T., Hargrove, W. L., Ralisch, R., Tessier, D., de Tourdonnet, S., ... dos Santos, D. R. (2013). Long-term effect of different soil management systems and winter crops on soil acidity and vertical distribution of nutrients in a Brazilian Oxisol. Soil Tillage Res., 133, 32-39. https://doi.org/10.1016/j.still.2013.05.009

Díaz-Pérez, J. C., Phatak, S. C., Ruberson, J., \& Morse, R. (2012). Mulches increase yield and improve weed control in no-till organic broccoli (Brassica oleracea var. botrytis). Acta Hort., 933, 337-342. https://doi.org/10.17660/ActaHortic.2012.933.43

Fedele. (2017). "Fast" transplanter. Lanciano, Italy: Fedele Costruzioni Meccaniche. Retrieved from http://www.fedelemario.com/trapiantatrice\%20fast.html

Harrigan, T. M., \& Rotz, C. A. (1994). Draft of major tillage and seeding equipment. ASAE Paper No. 941533. St. Joseph, MI: ASAE.

Kachman, S. D., \& Smith, J. A. (1995). Alternative measures of accuracy in plant spacing for planters using single-seed metering. Trans. ASAE, 38(2), 379-387.

https://doi.org/10.13031/2013.27843

Knezevic, A. (2008). Overlapping confidence intervals and statistical significance. Ithaca, NY: Cornell University, Cornell Statistical Consulting Unit. Retrieved from https://www.cscu.cornell.edu/news/statnews/stnews73.pdf

Kuznetsova, A., Brockhoff, P. B., \& Christensen, R. H. B. (2014). lmerTest: Tests for random and fixed effects for linear mixed effect models. Retrieved from http://CRAN.Rproject.org/package $=$ lmerTest

Manilla, R. D., \& Shaw, L. N. (1987). A high-speed dibbling transplanter. Trans. ASAE, 30(4), 904-908. https://doi.org/10.13031/2013.30496

Mazzoncini, M., Sapkota, T. B., Barberi, P., Antichi, D., \& Risaliti, R. (2011). Long-term effect of tillage, nitrogen fertilization, and cover crops on soil organic carbon and total nitrogen content. Soil Tillage Res., 114(2), 165-174. https://doi.org/10.1016/j.still.2011.05.001

Mitchell, J. P., Klonsky, K. M., Miyao, E. M., Aegerter, B. J., Shrestha, A., Munk, D. S., ... Turini, T. A. (2012). Evolution of conservation tillage systems for processing tomato in California's Central Valley. HortTech., 22(5), 617-626. https://doi.org/10.21273/horttech.22.5.617

Mitchell, J. P., Shrestha, A., Mathesius, K., Scow, K. M., Southard, R. J., Haney, R. L., ... Horwath, W. R. (2017). Cover cropping and no-tillage improve soil health in an arid irrigated cropping system in California's San Joaquin Valley, USA. Soil Tillage Res., 165, 325-335. https://doi.org/10.1016/j.still.2016.09.001

Morse, R. (1999). No-till vegetable production: Its time is now. HortTech., 9(3), 373-379. https://doi.org/10.21273/horttech.9.3.373

Morse, R. D., Vaughan, D. H., \& Belcher, L. W. (1993). Evolution of conservation tillage systems for transplanted crops: Potential role of the subsurface tiller transplanter (SST-T). Proc. Southern Cons. Tillage Conf. for Sustain. Agric. (pp. 145-151). Baton Rouge, LA: Louisiana Agricultural Experiment Station.

Motulsky, H. J. (2016). GraphPad curve fitting guide. San Diego, CA: GraphPad Software. Retrieved from http://www.graphpad.com/guides/prism/7/curvefitting/index.htm

Nandede, B. M., Raheman, H., \& Deore, H. V. (2014). Selection of suitable furrow opener and furrow closer for vegetable transplanter. AMA: Agric. Mech. Asia, Africa, Latin America, 45(2), 40-47.

Parish, R. L. (2005). Current developments in seeders and transplanters for vegetable crops. HortTech., 15(2), 346-351. https://doi.org/10.21273/horttech.15.2.0346

Prasanna Kumar, G. V., \& Raheman, H. (2008). Vegetable transplanters for use in developing countries: A review. Intl. J. Veg. Sci., 14(3), 232-255. https://doi.org/10.1080/19315260802164921

Prasanna Kumar, G. V., \& Raheman, H. (2012). Automatic feeding mechanism of a vegetable transplanter. Intl. J. Agric. Biol. Eng., $5(2), 20-27$.

R Core Team. (2013). R: A language and environment for statistical computing. Vienna, Austria: R Foundation for Statistical Computing.

RNAM. (1983). Test codes and procedures for farm machinery (Technical series 12, p. 219). Bangkok, Thailand: Regional Network for Agricultural Machinery.

Royston, P. (1995). Remark AS R94: A remark on algorithm AS 181: The W-test for normality. Appl. Stat., 44(4), 547-551. https://doi.org/10.2307/2986146

Russell, V. L., \& Herve, M. (2015). lsmeans: Least-squares means. $\mathrm{R}$ package ver. 2.16. Retrieved from http://CRAN.Rproject.org/package $=$ lsmeans

Singmann, H., Bolker, B., Westfall, J., Aust, F., Hojsgaard, S., Fox, J., ... Mertens, U. (2016). Analysis of factorial experiments. Retrieved from https://cran.rproject.org/web/packages/afex/afex.pdf

SSSA. (1987). Glossary of soil science terms. Madison, WI: Soil Science Society of America.

Tsuga, K. (2000). Development of fully automatic vegetable transplanter. Japan Agric. Res. Qtly., 34(1), 21-28.

Yoder, D. C., Cope, T. L., Wills, J. B., \& Denton, H. P. (2005). Notill transplanting of vegetables and tobacco to reduce erosion and nutrient surface runoff. J. Soil Water Cons., 60(2), 68-72. Retrieved from http://www.jswconline.org/content/60/2/68.abstract

Zamani, D. M. (2015). Development and evaluation of a vegetable transplanter. Intl. J. Tech. Res. Appl., 2(6), 40-46. 